\title{
Yoğun Bakım Ünitelerinde Sık Görülen Enfeksiyonlar, Gram-negatif Mikroorganizmalar, Antibiyotik Direnci
}

\author{
Common Infections in Intensive Care Units, Gram-negative Microorganisms, Antibiotic \\ Resistance
}

\author{
Arzu SSENOL ${ }^{1}$, Safak ÖZER BALİN ${ }^{2}$
}

\begin{abstract}
${ }^{1}$ Fethi Sekin Şehir Hastanesi, Enfeksiyon Hastalıkları ve Klinik Mikrobiyoloji Kliniği, Elazığ, Türkiye
${ }^{2}$ Fırat Üniversitesi Hastanesi, Enfeksiyon Hastalıkları ve Klinik Mikrobiyoloji Kliniği, Elazığ, Türkiye
\end{abstract}

\section{Özet}

Amaç: Bu çalışmada, yoğun bakım ünitelerinde yatan hastaların çeşitli klinik örneklerinden izole edilen Escherichia coli, Klebsiella pneumoniae, Pseudomonas aeruginosa ve Acinetobacter baumannii suşlarının dağılımı, ilaç direnç oranları ve bu oranların yıllara göre değişiminin saptanması, böylece akılcı antibiyotik uygulaması ve direncin önlenmesine katkı sağlanması amaçlanmıştır.

Gereç ve Yöntemler: İzole edilen suşların kolistin, tigesiklin, meropenem, imipenem ve trimetoprim-sulfametoksazol direnç oranları retrospektif olarak incelenmiştir. Üreyen bakterilerin identifikasyonu ve antibiyotik duyarlılık testleri VITEK 2 Compact ve MicroScan WalkAway 96 otomatize sistemi (kolistin için mikrotüp dilüsyon ) kullanılarak belirlenmiş ve The European Committee on Antimicrobial Susceptibility Testing (EUCAST) Institute önerilerine göre değerlendirilmiştir.

Bulgular: Yoğun bakım ünitelerinde en sık gözlenen mikroorganizma A. baumannii (\%57.2) idi. Hastane enfeksiyonu olarak, \% 94.1 oranında ventilatörle ilişkili pnömoni, \%45.2 oranında santral venöz kateterle ilişkili kan dolaşım enfeksiyonu ve \%44 oranında kateter ilișkili üriner sistem enfeksiyonu görülmüştür. A.baumannii, P.aeruginosa ve K.pneumoniae' da meropenem, imipenem ve trimetoprim-sülfametoksazol direnç oranları yüksek bulunmuştur. Tüm mikroorganizmalara karşı en düşük direnç oranına sahip antibiyotik kolistin olarak saptanmıştır.

Sonuç: En yüksek duyarlılığa sahip antimikrobiyalin kolistin olması nedeniyle, özellikle çok ilaca dirençli suşlara karşı kolistin tek başına veya diğer antibiyotiklerle kombine olarak kullanılabilir. E.coli enfeksiyonlarında karbapenemler ve trimetoprim-sulfametoksazol duyarlı suşlarda kullanılabilir. Antibiyotik duyarlılık test sonuçlarına göre tedavi başlanması ve düzenli sürveyans takibinin yapılması, yoğun bakım ünitelerinde uygun antibiyotik kombinasyonları seçilmesine ve dirençli mikroorganizmaların azaltılmasına katkı sağlayacaktır.

Anahtar Kelimeler: Antimikrobiyal ilaç direnci, Yoğun bakım üniteleri, Gram-negatif mikroorganizmalar

\section{Abstract}

Objective: The aim of the study was to determine the distribution of E.coli, K pneumoniae, P.aeruginosa, and A.baumannii strains isolated from various clinical samples of patients hospitalized in intensive care units (ICUs) as well as the drug resistance rates and the change of these rates over the years, thus contributing to rational antibiotic use and prevention of resistance.

Material and Methods: The resistance rates of the isolated strains against colistin, tigecycline, meropenem, imipenem, and trimethoprim-sulfamethoxazole were retrospectively analyzed. Identification and antibiotic susceptibility tests of the microorganisms were done using the VITEK 2 Compact and MicroScan WalkAway 96 automated system (microtube dilution for colistin) and evaluated according to the Clinical and Laboratory Standards Institute recommendations.

Results: The most common microorganism in ICUs was A. baumannii (52.2\%). As hospital infections, 94.1\% ventilator-associated pneumonia, 45.2\% central venous catheter-related bloodstream infection, and 44\% catheter-related urinary system infection were observed. Meropenem, imipenem, and trimethoprim-sulfamethoxazole resistance rates were found to be high in A. baumannii, P. aeruginosa, and K. pneumoniae. The antibiotic with the lowest resistance rate against all microorganisms was colistin.

Conclusion: Since the most susceptible antimicrobial agent is colistin, it can be used alone or in combination with other antibiotics, especially against highly drug-resistant strains. For E. coli infections, carbapenems and trimethoprim-sulfamethoxazole can be used in susceptible strains. Starting treatment and following regular surveillance according to the antibiotic susceptibility test results will contribute to the selection of appropriate antibiotic combinations in ICUs and the reduction of resistant microorganisms.

Keywords: Antimicrobial drug resistance, Intensive care units, Gram-negative microorganisms

Yazışma Adresi: Arzu ŞENOL, Enfeksiyon Hastalıkları ve Klinik Mikrobiyoloji Departmanı, Fethi Sekin Şehir Hastanesi, Ulukent Mah. Onbaşı Cad. No: 99 Elazı̆̆ Türkiye, Telefon: +90 50529759 16, Mail: asenol2017@gmail.com

ORCID No (Sirasıyla): 0000-0002-8537-0195, 0000-0002-3722-4660

Geliş tarihi: 23.01.2020

Kabul tarihi: 26.06 .2020

DOI: $10.17517 /$ ksutfd.671762 


\section{GIRIŞ}

Yoğun bakım üniteleri (YBÜ), hastane enfeksiyonlarının (HE) en sık görüldüğü, mortalite oranlarının en yüksek olduğu, mekanik ventilasyon, trakeostomi, kateter gibi invaziv girişimlerin sık uygulandığı, geniş spektrumlu antibiyotiklerin yaygın kullanıldığ dirençli patojenlerle tedavisi güç enfeksiyonlar ortaya çıkabilmektedir (1).

Yoğun bakım ünitelerinde gelişen HE’lerinin etkenleri ve direnç profilleri hastaneler arasında zaman içerisinde değişiklik gösterebilmektedir (2). Hastane kökenli enfeksiyonlarda klinik önemi olan gram negatif bakteriler (GNB) çoğunlukla Klebsiella pneumoniae, Escherichia coli, Pseudomonas aeruginosa ve Acinetobacter baumannii' dir (3). Genişlemiş spektrum beta-laktamaz (GSBL) üretimi ile gelişen direnç, enterik GNB'lerde en önemli direnç mekanizmasıdır. Bu enzim en s1k K.pneumoniae ve E.coli'de bulunur, bu mikroorganizmaların neden olduğu ciddi enfeksiyonların tedavisinde karbapenemler ilk seçilen ajanlardır. Ancak bu ajanların sık kullanımı direnç sorununu da beraberinde getirmiştir (4). Hastane enfeksiyonu etkeni nonfermentatif organizmalar içinde yer alan P.aeruginosa ve Acinetobacter spp. izolatlarında da tedavide kullanılan antibiyotiklere karşı artan oranda direnç görülmekte ve tedavi seçeneği azalmaktadır. P.aeruginosa suşlarında, GSBL, efluks pompaları, dış membran porin kaybı ve hedef bölge mutasyonları gibi mekanizmalarla direnç gelişmektedir (5).

Son yıllarda dirençli bakterilerle gelişen HE'ları tüm dünyada gözlenen bir sorundur. Antibiyotiklere dirençli etkenlerin neden olduğu bu enfeksiyonlar, hem morbidite ve mortaliteyi arttırmakta hem de hastanede yatış süresinde uzama ve ciddi komplikasyonlara neden olabilmektedir (5). $\mathrm{Bu}$ enfeksiyonların tedavisinde antibiyotik seçeneklerimiz kısıtlıdır. Bundan dolayı, antibiyotik direnç profilinin bilinmesi, hem antibiyotik seçimi hem de direnç oranlarını azaltmak için gerekmektedir $(1,6)$.

$\mathrm{Bu}$ çalışmada, bir eğitim ve araştırma hastanesinde üç y1llık süre içinde YBÜ'lerde yatan hastaların çeşitli klinik örneklerinden izole edilen E.coli, K.pneumoniae, P.aeruginosa ve A.baumannii suşlarının dağılımı, ilaç direnç oranları ve bu oranların yıllara göre değişiminin saptanması, böylece akılcı antibiyotik uygulanmasına ve direncin önlenmesine katkı sağlanması amaçlanmıştır.

\section{GEREÇ ve YÖNTEMLER}

Bu çalışmaya üçüncü basamak hizmet veren YBÜ'leri dahil edilmiştir. 2015 -2018 yılları arasında Anestezi ve Reanimasyon, Dahiliye, Gögüs Hastalıkları, Genel Cerrahi ve Nöroloji YBÜ’lerindeki çeşitli klinik materyallerden elde edilen izolatlar değerlendirilmiştir. Hastane enfeksiyonu tanısı konulmasında, Hastalıktan Koruma ve Önleme Merkezi (Center for Disease Control and Prevention, CDC) tarafindan belirlenen tanımlamalar esas alınmıştır(7).

E.coli, K.pneumoniae, P.aeruginosa ve A.baumannii suşlarının kolistin, tigesiklin, meropenem, imipenem ve trimetoprim-sulfametoksazol direnç oranları retrospektif olarak incelenmiştir. Üreyen mikroorganizmaların etken-kolonizasyon ayırımı CDC kriterlerine göre yapılmıştır (7). Kan kültür örnekleri BACT/ALERT 3D (Biomerieux, Fransa) otomatize sisteminde takip edilmiş, üreme saptanan örnekler gram boyama ile değerlendirilmiştir. Eş zamanlı olarak idrar ve endotrakeal aspirat örnekleri gibi \%5 koyun kanlı agar (bioMerieux, France) ve eozin metilen mavisi (EMB) agarda (bioMerieux, France) $35^{\circ} \mathrm{C}$ 'de 18 -24 saat inkübe edilmiştir. Üreyen bakterilerin identifikasyonu ve antibiyotik duyarl111k testleri VITEK 2 Compact ve MicroScan WalkAway 96 otomatize sistemi (kolistin için mikrotüp dilüsyon) kullanılarak EUCAST verilerine göre değerlendirilmiştir(8). Hasta verilerine aktif ve laboratuvara dayalı yapılan sürveyans verilerinden ulaşılmıştır. YBÜ'lerindeki bir yıllık HE hızı, HE'larının sistemlere göre dağılımı, enfeksiyon etkenleri ve bu etkenlerin antibiyotik direnci belirlenmiştir (orta duyarlı ("intermediate") suşlar dirençli kabul edilmiştir). Meropenem, imipenem ve kolistin dirençli suşların minimum inhibitör konsantrasyonu EUCAST önerilerine göre değerlendirilmiştir (8). Bu çalışma Helsinki Deklerasyonu prensiplerine uygun olarak gerçekleştirilmiştir. Çalışma için Fırat Üniversitesi Tıp Fakültesi Klinik Araştırmalar Etik Kurulu'ndan 18.01.2018 tarih ve 07 sayılı kararla onay alınmıştır.

İstatistiksel analiz: $\mathrm{Bu}$ çalışmada elde edilen verilerin istatistik analizi için "SPSS for 22" (Statistical Package for Social Sciences; version 22, SSPS Inc, Chicago, IL, USA) programı kullanılmıştır. Normal dağılıma uyan sürekli değişkenlerin analizinde Student's t testi, kategorik verilerin analizinde ise "ki-kare testi" kullanılmıştır. Sayısal veriler ortalama \pm standart sapma olarak, kategorik veriler $\%$ olarak ifade edilmiştir. İstatistiksel karşılaştırmalarda $\mathrm{P}<0.05$ değeri anlamlı olarak kabul edilmiştir.

\section{BULGULAR}

İzole edilen suşların 107'si (\%57.2) A.baumannii, 48'i (\%25.7) P.aeruginosa, 9’u (\%4.8) E.coli, 23'ü (\%12.3) K.pneumoniae idi. Suşların 160`^1 (\%85.5) Anestezi YBÜ’lerinden elde edilmiştir. En sik gözlenen mikroorganizma $A$. baumannii (\%57.2) olmuştur. Suşların izole edildikleri birimlere göre dağılımı, Tablo 1'de verilmiştir. Yoğun bakım üniteleri arasında izole edilen suşlar açısından istatistiksel olarak anlamlı bir farklılık gözlenmemiştir ( $\mathrm{p}>0.05)$. 


\section{Tablo 1. Suşların izole edildikleri YBÜ’lere göre dağlımları.}

\begin{tabular}{|l|c|c|c|c|}
\hline & A.baumannii & P.aeruginosa & E. coli & K.pneumoniae \\
\hline Anestezi ve Reanimasyon YBÜ & $90(84.1)$ & $46(95.8)$ & $6(66.7)$ & $18(78.3)$ \\
\hline Dahiliye YBÜ & $2(1.9)$ & - & - & $1(4.3)$ \\
\hline Göğ̈̈s Hastalıkları YBÜ & $12(11.2)$ & $2(4.2)$ & $1(11.1)$ & $4(17.4)$ \\
\hline Genel cerrahi YBÜ & $3(2.8)$ & - & $1(11.1)$ & - \\
\hline Nöroloji YBÜ & - & - & $1(11.1)$ & - \\
\hline YBÜ: Yoğun Bakım Ünitesi & & & \\
\hline
\end{tabular}

Yoğun bakım ünitelerinde en s1k görülen HE'leri, ventilatör ilişkili pnömoni (VİP) (\%95.2) iken bunu santral venöz kateter ilişkili kan dolaşım enfeksiyonu (SVKI-KDE) (\%45.1) ve kateter ilişkili üriner sistem enfeksiyonu (Kİ-ÜSE) (\% 38.6) izlemiştir. Hastane enfeksiyonlarına göre mikroorganizmaların dağılımı, Tablo 2'de gösterilmiştir. Yoğun bakım üniteleri arasında mikroorganizmaların dağılımı açısından istatistiksel olarak anlamlı bir faklılık gözlenmemiştir(p $>0.05)$.
Çalışma boyunca 30020 yoğun bakım gününde izlenen 5204 hastada 269 HE epizodu tanımlanmıştır. Hastane enfeksiyonu hızı \% 27.3 olarak hesaplanmıştır.

Bu çalışmada, A.baumannii, P.aeruginosa ve K.pneumoniae'da meropenem, imipenem ve trimetoprim-sülfametoksazol direnç oranı yüksek, E.coli'de nisbeten daha düşük bulunmuştur. Tüm mikroorganizmalarda en düşük direnç oranı kolistinde gözlenmiştir. P. aeruginosa dışındaki diğer suşlarda, tigesikline direnç oranı düşük bulunmuştur. İzole edilen suşları karşı antibiyotik direnç oranları, Tablo 3'te verilmiştir.

\section{Tablo 2. Hastane enfeksiyonlarına göre etkenlerin dağılım oranları}

\begin{tabular}{|l|c|c|c|c|c|} 
& $\begin{array}{l}\text { VİP/NP } \\
\mathrm{n}(\%)\end{array}$ & $\begin{array}{l}\text { LTK-KDE } \\
\mathrm{n}(\%)\end{array}$ & $\begin{array}{l}\text { SVKİ-KDE } \\
\mathrm{n}(\%)\end{array}$ & $\begin{array}{l}\text { Kİ-ÜSE } \\
\mathrm{n}(\%)\end{array}$ & $\begin{array}{l}\text { CAE } \\
\mathrm{n}(\%)\end{array}$ \\
\hline A. baumannii & $71(59.7)$ & $8(36.4)$ & $19(30.6)$ & $7(9.3)$ & - \\
\hline P. aeruginosa & $31(26.9)$ & - & $1(1.6)$ & $15(20)$ & $1(33.3)$ \\
\hline E. coli & $2(1.7)$ & - & $1(1.6)$ & $5(1.3)$ & $1(33.3)$ \\
\hline K. pneumoniae & $8(6.9)$ & $1(4.5)$ & $7(11.3)$ & $6(8)$ & $1(33.3)$ \\
\hline Toplam & $112(95.2)$ & $9(40.9)$ & $28(45.1)$ & $33(38.6)$ & - \\
\hline
\end{tabular}

CAE: Cerrahi alan enfeksiyonu; Kİ-ÜSİ: Kateter ilişkili üriner sistem enfeksiyonu; LTK-KDE: Laboratuar tarafindan kanıtlanmış KDE; SVKİ-KDE: Santral venöz kateter ilişkili kan dolaşım enfeksiyonu; VİP/NP: Ventilatör ilişkili pnömoni/ nozokomiyal pnömoni

Tablo 3. P.aeruginosa, A.baumannii, E.coli ve K.pneumoniae suşlarına karşı imipenem, meropenem, tigesiklin, kolistin ve trimetoprim-süllfametoksazolün yıllara göre direnç oranları

\begin{tabular}{|c|c|c|c|c|c|c|c|c|c|c|c|c|}
\hline & \multicolumn{3}{|c|}{ A. baumannii } & \multicolumn{3}{|c|}{ P. aeruginosa } & \multicolumn{3}{|c|}{ E. coli } & \multicolumn{3}{|c|}{ K. pneumoniae } \\
\hline Antibiyotik & 2015 & 2016 & 2017 & 2015 & 2016 & 2017 & 2015 & 2016 & 2017 & 2015 & 2016 & 2017 \\
\hline & $\%$ & $\%$ & $\%$ & $\%$ & $\%$ & $\%$ & $\%$ & $\%$ & $\%$ & $\%$ & $\%$ & $\%$ \\
\hline İmipenem & 92.3 & 100 & 100 & 100 & 75 & 66.6 & 0 & 0 & 50 & 0 & 100 & 100 \\
\hline Meropenem & 100 & 100 & 94.4 & 100 & 50 & 63.3 & 0 & 0 & 50 & 0 & 83.3 & 62.5 \\
\hline Tigesiklin & 72 & 46 & 14.8 & & & & & & & & & 29 \\
\hline Kolistin & 7.7 & 0 & 3.4 & 0 & 1 & 12.5 & & & & & 16.7 & \\
\hline Trim-sulf & 77.7 & 73 & 62.9 & 100 & 100 & 100 & 0 & 0 & 33.3 & 100 & 17 & 70 \\
\hline
\end{tabular}

Trim-sulf: Trimetoprim-sulfametaksazol 


\section{TARTIŞMA}

Hastane enfeksiyonları, hem dünyada hem de ülkemizde tedavi başarısını olumsuz yönde etkilemektedir (9). Yoğun bakım ünitelerinde HE gelişme riski, hastanelerin diğer birimlerinden 5-7 kat daha fazladır ve gelişen enfeksiyonların \% 60'ını VİP, Kİ-ÜSE ve SVKİ-KDE olușturmaktadır (2, 10). "European Prevalence of Infection in Intensive Care" (EPIC II) çalışmasında; 13.796 erişkin hastanın \% 51'inin enfekte ve bu hastaların \% 64'ünün akciğer kaynaklı olduğu bildirilmiştir(11). Ak ve ark. (12) bir yıllık prospektif kohort çalışmasında, YBÜ’lerinde HE oranlarını \%36.3 bakteremi, \%30.4 VİP, \%18.5 Kİ-ÜSE, \%7.4 SVKİ-KDE, \%5.9 kutanöz enfeksiyon ve \%1.3 menenjit olarak belirtmişlerdir. Bu çalışmada, YBÜ'lerinde en sık görülen HE’u, VİP (\%95.2) idi. Bunu \% 45.2 ile SVKİ-KDE ve \% 38.6 ile Kİ-ÜSİ izlemiştir.

Köksaldı ve ark.'nın (13)çalışmasında, VIP'te $A$. baumannii, Kİ-ÜSE'de E.coli ve Candida spp., SVKİ-KDE'da gram-pozitif koklar, en sık etken olarak saptanmıştır. Yetmiş beş ülkenin 1265 YBÜ’ni içeren EPIC II çalışmasında enfekte hastalarda pozitif izolatların \%62'si GNB, \%47'si gram-pozitif bakteriler, \%19'u mantarlar olarak tespit edilmiştir (11). Bu çalışmada, en sık Vİ'de \%59.7 oranında ve SVKİ-KDE'unda \% 30.6 oranında A.baumannii, Kİ-ÜSE'da \% 20 oranında P.aeruginosa saptanmıştır.

Ülkemizde HE hızlarının, sürveyans yöntemleri ve enfeksiyon kontrol önlemlerine uyum ile ilişkili olarak \%5.3 ve $\% 88.9$ arasında değişebildiği bildirilmiştir (14). Bu çalışmada, HE hızı \% 27.3 olarak hesaplanmıştır.

Yoğun bakım ünitelerinde etken mikroorganizmaların antimikrobiyal duyarlılıklarını belirlemek, hem tedavi seçiminde yol göstermek hem de mortalite ve morbiditeyi azaltmak için önemlidir $(2,13)$. P.aeruginosa ve A.baumannii türlerinin çok ilaca dirençli (ÇID) suşlarında son yıllarda ciddi artışlar olmuştur(15). Karbapenemler, A.baumannii enfeksiyonlarının tedavisinde etkili antibiyotikler olmasına rağmen karbapenem dirençli A.baumannii izolatlarının oranı giderek artmıştır (16). Ülkemizde Acinetobacter enfeksiyonları için farklı direnç oranları bildirilmiş olup, imipenem için bu oran \%8-59 aralığında değişirken, meropenem için \%18-47 arasında değişmiştir (17). Klebsiella spp.'de ise en etkili antibiyotikler amikasin ve imipenem olarak belirlenmiştir. Yine Moolchandani ve ark.'nın (18) yaptıkları çalışmada, YBÜ’nden izole edilen Pseudomonas spp. için meropenem direnci \% 56, Acinetobacter spp. için \% 83.5 olarak saptanmıştır. Karbapenemlere karşı artan bu direnç oranı beraberinde diğer antibiyotiklere de direnç sorununu getirdiği için elde bulunan tedavi seçenekleri azalmıştır. Bu çalışmada 2015-2018 yılları arasında imipenem direnç oranları, A.baumannii'de \%92.3-100, P.aeruginosa'da \%66.6-100, E.coli'de \%0-50, K.pneumoniae' da \%0-100 arasında değişmişken; meropenem direnç oranları, A.baumannii'de \%94.4-100, P.aeruginosa'da \%50-100,E.coli'de \%0-50 ve K.pneumoniae'da \%62.5-83.3 arasında değişim göstermiştir. İmipenem ve meropenem direnç oranlarının A.baumannii ve P.aeruginosa türlerinde zamanla arttığı ve diğer benzer çalışma sonuçlarından yüksek olduğu görülmüştür. $\mathrm{Bu}$ da hastanemizde 3 . Basamak YBÜ hizmeti veren YBÜ'lerinin sayısının artmas1na ve özellikle komplike (ileri yaş ve kronik hastalıkları olan ) hasta yatış oranının fazla olmasına bağlı olabilir.

Karbapenem direncinin artması, uzun yıllar önce yan etkileri nedeniyle kullanımı kısıtlanan kolistini, önemli bir tedavi seçeneği haline getirmiştir. Yapılan çalışmalarda kolistinin tek başına kullanılamayacağı, mutlaka başka bir antibiyotik ile birlikte kullanılması gerektiği belirtilmiştir. Kolistin, polimiksin ailesinden katyonik bir antimikrobiyal peptiddir. Nefrotoksisite ve nörotoksisitesi nedeniyle yıllarca kullanılmamış, ÇID GNB'lerin artmasıyla birlikte yeniden kullanıma girmiştir (16). A.baumannii izolatlarına karşı en etkili antimikrobiyal ajanın kolistin olduğu bildirilmiştir. Ancak son yıllarda kolistin direnci de artmıştır(19). Kurtoğlu ve ark.'nın (20) çalışmasında \%5 oranında kolistin direnci bildirilmiştir. Ülkemizde bu ilaca karşı direnç henüz yüksek seviyede görülmemiştir. Bu çalışmada, 2015-2018 yılları arasında kolistin direnç oranı A.baumannii' de \%0-7.7, P.aeruginosa'da \% 0-12.5, K. pneumoniae'da \% 16.7 olarak saptanmıştır.

Tigesiklin bakteriyostatiktir, in vitro olarak aerobik ve anaerobik dirençli gram-negatif ve pozitif bakterilere etkilidir. Proteus, Providencia ve $P$. aeruginosa'nın tigesikline doğal olarak dirençli olduğu görülmüştür (21). Tigesiklin ÇİD A. baumannii enfeksiyonlarının tedavisinde alternatif ilaç seçeneklerinden biridir. Öte yandan P.aeruginosa'ya karşı aktivitesi olmadığından ve serum konsantrasyonunun düşük olduğundan bakteremilerde tercih edilmemiştir. $\mathrm{Bu}$ nedenler, tigesiklin kullanımını kısıtlamıştır. Ancak KDE'larında da etkili olduğu farklı çalışmalarla gösterilmiştir (21). Çok ilaca direncin yaygın olduğu kurumlarda tigesiklinin kolistin veya aminoglikozidler ile kombine kullanımı önerilmiştir (5). Kurtoğlu ve ark. (20) tigesiklin direncini 2009 ve 2010 'da sırasıyla \%12 ve \%21 olarak saptamışlardır. Tigesiklin duyarlılığının değerlendirildiği başka bir çalışmada ise GSBL üreten E.coli ve K.pneumoniae' da karbapenemler kadar etkin olduğu bulunmuştur(4). Lu ve ark. (22), 622 GSBL pozitif GNB'lerin tigesiklin duyarlılığını araştırmışlar; E.coli'de \%99.6, K.pneumoniae'da \%98.5, Proteus mirabilis'te $\% 73.3$ ve K.oxytoca' da \%100 olarak bildirmişlerdir. Bu çalışmada ise K.pneumoniae' da tigesiklin direnç oranı, 2017 yılında \% 29 bulunmuştur. A.baumannii'de tigesiklin direnç oranının zaman içerisinde azaldığı görülmüştür (2017 de \% 14.8). Bu durum, bakteremi ve üriner sistem enfeksiyonunda tigesiklin kullanımının kısıtlı olması ve ÇİD suşlarda tedavide kolistinin daha sık kullanılmış olmasıyla açıkşlanabilir.

Falagas ve ark. (23)'nın yaptığı çalışmada, Çi̇D Acinetobacter spp. enfeksiyonlarında trimetoprim-sulfametoksazol direnç oranlarının \%4-98 arasında değiştiği gösterilmiştir. Yine aynı metaanalizde, Çİ Acinetobacter spp. suşlarının \% 70'inin, karbapenem dirençli suşların \%80'inin trimetoprim-sülfametoksazole dirençli olduğu gösterilmiştir. Bunun- 
la birlikte, yedi olguda trimetoprim-sulfametoksazolün diğer antibiyotikler ile kombine tedavisinin kür sağladığı gösterilmiştir. Bu çalışmada, P.aeruginosa' da trimetoprim-sulfametoksazol direnç oranı \% 100; A.baumannii'de \%62.9-77.7, E.coli'de \%0-33.3 ve K.pneumoniae'da \%16.6-70 arasinda saptanmıştır. E.coli ve K.pneumoniae'da, bu düşük direnç oranları, trimetoprim-sulfametoksazol kullanım oranının düşük olmasına bağlı olabilir.

Sonuç olarak, antibiyotiklerin kontrolsüz ve yanlış kullanımı direncin artmasına neden olmuş, ÇİD GNB enfeksiyonlarının tedavisinde seçeneklerimiz giderek azalmıştır. Bu çalışmada, tüm suşlarda meropenem, imipenem ve trimetoprim-sulfametoksazol için direnç oranları yüksek bulunmuştur. E. coli 'de imipenem ve meropenem direnç oranları, diğer suşlardan daha düşük saptanmıştır. Tigesiklin için, P.aeruginosa dişındaki diğer mikroorganizmalarda daha düşük oranda direnç tespit edilmiştir. Bu mikroorganizmalara karşı en yüksek duyarlılığa sahip antimikrobiyal ajanın kolistin olması nedeniyle, özellikle ÇİD suşlara karşı kolistin ve kolistin ile diğer antibiyotik kombinasyonları tedavide kullanılabilir. Antibiyotik duyarlılık test sonuçlarına göre tedavi başlanması ve düzenli sürveyans takibinin yapılması, YBÜ’lerinde uygun antibiyotik kombinasyonları seçilmesine ve dirençli mikroorganizmaların azaltılmasına katkı sağlayacaktır.

Çıkar çatışması ve finansman beyanı: Bu çalışmada çıkar çatışması yoktur ve finansman desteği alınmamıştır.

Araştırmacıların Katkı Oranı Beyan Özeti: Yazarlar makaleye eşit katkı sağlamış olduklarını beyan ederler.

\section{KAYNAKLAR}

1. Aydemir Ö, Demiray T, Köroğlu M, Aydemir Y. Yoğun bakım ünitelerinde yatan hastaların endotrakeal aspirat örneklerinden izole edilen bakterilerin tanımlanması ve antibiyotik duyarlılıkları. Online Türk Sağlık Bilimleri Derg. 2016; 1(4): 1-8.

2. Çetin ES, Kaya S, Pakbaş İ, Demirci M. Yoğun bakım ünitelerinde yatan hastalardan izole edilen mikroorganizmalar ve antibiyotik duyarlılıkları, İnönü Üniversitesi Tip Fakültesi Dergisi. 2007; 14(2): 69-73.

3. Nicasio, A.M, Kuti JL and Nicolau DP. The current state of multidrug-resistant gram-negative bacilli in North America. Pharmacotherapy. 2008; 28(2): 235-49.

4. Falagas ME, Karageorgopoulos DE. Extended-spectrum beta-lactamase-producing organisms. J Hosp Infect. 2009; 73(4): 345-54.

5. Nordmann P, Cuzon G, Naas T. The real threat of Klebsiella pneumoniae carbapenemase-producing bacteria. Lancet Infect Dis. 2009; 9(4): 228-36.

6. Vasudevan A, Mukhopadhyay A, Li J. Prediction tool for nosocomial multi-drug resistant gram-negative bacilli infections in critically ill patients prospective observational study. BMC Infect Dis. 2014; 25(14): 615.

7. Garner JS, Jarvis WR, Emori TG. CDC definitions for nosocomial infections, 1988. Am J Infect Control. 1988; 16(3): 128-40.

8. Clinical and Laboratory Standards Institute. Performance Stan- dards for Antimicrobial Susceptibility Testing; Twenty-Third Informational Supplement (M100-S23). Wayne, PA: CLSI 2013:1-205.

9. Çiftçi İH, Çetinkaya Z, Aktepe OC. Klinik örneklerden izole edilen Pseudomonas aeruginosa suşlarının antibiyotiklere duyarlılıkları. Türk Mikrobiyoloji Cemiyeti Dergisi. 2005; 35(2): 98-102.

10. Köksal İ. Yoğun bakımda gram pozitif bakteri sorunu. ANKEM Dergisi. 2009; 23(2): 143-7.

11. Vincent JL, Rello J, Marshall J. International study of the prevalence and outcomes of infection in intensive care units: Results of the European prevalence of infection in intensive care (EPIC II) study. JAMA. 2009; 302(21): 2323-9.

12. Ak O, Batırel A, Özer S, Çolakoğlu S. Nosocomial infections and risk factors in the intensive care unit of a teaching and research hospital: A prospective cohort study. Med Sci Monit. 2011; 17(5): 29-34.

13. Köksaldı MV, Evirgen Ö, Yula E. Mustafa Kemal Üniversitesi Tıp Fakültesi Yoğun bakım ünitesi’nde 2011 yılında sağlık hizmeti ile ilişkili infeksiyonların değerlendirilmesi. ANKEM Dergisi. 2012; 26(3): 137-42.

14. Yılmaz GR, Çevik MA, Erdinç FŞ, Tüfek N. Nöroloji Yoğun bakım ünitesinde gelişen nozokomiyal infeksiyon risk faktörlerinin değerlendirilmesi. Hastane İnfeksiyonları Dergisi. 2002; 6(1): 24-31.

15. Paterson DL. Serious infections in the intensive care unit: Pseudomonas aeruginosa and Acinetobacter baumannii. Clin Infect Dis. 2006;43(2):41-2.

16. Timurkaynak F, Can F, Azap OK, Demirbilek M, Arslan H, Karaman SO. In vitro activities of non-traditional antimicrobials alone or in combination against multidrug-resistant strains of Pseudomonas aeruginosa and Acinetobacter baumannii isolated from intensive care units. Int J Antimicrob Agents. 2006;27(3):224-8

17. Eroğlu C, Ünal N, Karadağ A. Acinetobacter species isolated from various clinical specimens between 2006-2011 years and their susceptibilities against antibiotics. Journal of Turkish Hygiene and Experimental Biology. 2016; 73(1): 25-32.

18. Moolchandani K, Sastry AS, Deepashree R. Antimicrobial Resistance Surveillance among Intensive Care Units of a Tertiary Care Hospital in Southern India. J Clin Diagn Res. 2017; 11(2): 1-7.

19. Lee CR, Lee JH, Park M. Biology of Acinetobacter baumannii: Pathogenesis, Antibiotic Resistance Mechanisms, and Prospective Treatment Options. Front Cell Infect. Microbiol. 2017; 7(55):1-35.

20. Kurtoğlu MG, Opuş A, Kaya M. Bir Eğitim ve Araştırma Hastanesi'nde klinik örneklerden izole edilen Acinetobacter baumannii suşlarında antibakteriyel direnç (2008-2010). ANKEM Dergisi. 2011; 25(1): 35-41.

21. Rose WE, Rybak MJ. Tigecycline: first of a new class of antimicrobial agents. Pharmacotherapy. 2006; 26(8): 1099-1110.

22. Lu CT, Chuang YC, Sun W. Nationwide survelliance in Taiwan of the in-vitro activity of tigecycline against clinical isolates of extended-spectrum beta-lactamase-producing Enterobacteriaceae. Int Antimicrob Agents. 2008; 32(5): 179-83.

23. Falagas ME, Vardakas KZ, Roussos NS. Trimethoprim/sulfamethoxazole for Acinetobacter spp.: areview of current microbiological and clinical evidence. Int J Antimicrob Agents. 2015; 46(3): 231-41. 